\title{
Vasculite ocular e elevação da imunoglobulina E - um desafio na investigação etiológica
}

\author{
Ocular vasculitis and elevated immunoglobulin E - \\ a challenge in etiological investigation
}

Heloisa Ribeiro, Manuela Alves
Centro Hospitalar de Entre o Douro e Vouga

\begin{abstract}
Resumo
A vasculite retiniana consiste em inflamação intra-ocular que afeta os vasos retinianos e pode ocorrer de forma localizada ou associada a diversas patologias sistémicas, de origem inflamatória ou neoplásica. Descreve-se o caso de uma mulher de 29 anos, com vasculite retiniana de predomínio venoso, infeções respiratórias e urinárias de repetição, sem história de atopia, com prova de Mantoux e Interferon Gamma Realease Assay positivos, elevação marcada e persistente da lgE (> $5000 \mathrm{lU} / \mathrm{L})$, com restante estudo imune e genético (mutações STAT 3 e DOCK 8) negativo. Levantando-se a hipótese de tuberculose ocular, esta torna-se pouco provável dado 0 aspeto das lesões em angiografia e evolução dos níveis de lgE, podendo ser o quadro enquadrado na Síndrome de Hiper lgE, cujo diagnóstico é altamente provável tendo em conta o score de diagnóstico de critérios clinicolaboratoriais, cuja heterogeneidade decorre de alterações genéticas diferentes, sendo o seu tratamento dirigido à prevenção e tratamento de infecções.
\end{abstract}

Palabras clave: Imunoglobulina E, Inmunodeficiencia, Vasculitis retiniana

\section{Introdução}

A vasculite retiniana consiste numa doença inflamatória que envolve os vasos retinianos. Pode ocorrer de forma isolada ou em contexto de múltiplas patologias sistémicas, podendo mesmo constituir a sua primeira manifestação. Obriga, por isso, ao estudo etiológico adequado, de modo a poder ser proporcionado, quando disponível, tratamento adequado. ${ }^{1}$

\section{Descrição de Caso}

Apresenta-se 0 caso de uma mulher de 29 anos, com parceiro sexual estável desde longa data, operária fabril. Como antecedentes pessoais referia síndroma depressivo; lombalgia com irradiação ao membro inferior esquerdo, seguida em consulta de Ortopedia, cujo estudo revelou atitude escoliótica lombar, muito discreta e dextro-convexa, e desencastramento de L5 parcial e discreto, passível de condicionar alguma sobrecarga funcional em L4-L5; tumefação tibial esquerda pós-traumática compatível com displasia fibrosa da cortical; esofagite grau I, hérnia do hiato e gastrite crónica com refluxo biliar, com biópsia positiva para Helicobacter pylori em 2011; litíase renal com episódio de cólica renal em 2011; infeções do trato urinário de repetição e displasia de baixo grau do colo uterino, seguida em consulta de Ginecologia/ Obstetrícia. Negava história de tuberculose pulmonar. Tinha uma irmã com síndroma de hipermobilidade articular benigna. Sem história de viagens para o exterior ou outros ante-

\begin{abstract}
Retinal vasculitis is a sight-threatening intraocular inflammation affecting the retinal vessels, which may occur as a localized condition or associated with systemic inflammatory or neoplasic disorders. We present the case of a 29 years old woman with venous retinal vasculitis, recurrent urinary and respiratory tract infections, without medical record of atopy, with positive Mantoux and Interferon Gamma Release Assay, elevated IgE (>5000IU/L), with negative auto-immune and genetic testing for STAT 3 and DOCK 8 mutations. Considering the hypothesis of ocular tuberculosis, this becomes unlikely given the appearance of the lesions on angiography and evolution of lgE levels. Moreover, the entire picture could be classified as the rare Hyper IgE Syndrome, according the scoring system comprising both clinical and laboratory diagnostic criteria, whose heterogeneity arises from different genetic alterations. There is no specific treatment, so the goal is the prevention and treatment of infections.
\end{abstract}

Keywords: E Immunoglobulin, Immunodeficiency, Retinal vasculitis

cedentes pessoais ou familiares de relevo. Sem história de atopia. Descrevia acne na adolescência, mantendo pequenas pápulas na face na idade adulta; sem outras alterações cutâneas, das mucosas ou faneras. Referia obstrução nasal e coriza mucosa, ocasionalmente mucopurulenta, frequentes. Negava história de poliartralgias, fenómeno de Raynaud, fotossensibilidade, sintomas sistémicos (nomeadamente sintomas B) e sintomatologia do foro cardíaco. Desde 2005 que apresentava trombocitopenia ligeira (105000/uL). Encontrava-se habitualmente medicada com anticoncepcional oral. A doente foi observada em consulta de Medicina Interna após ter sido encaminhada por Oftalmologia por redução progressiva da acuidade visual por vasculite retiniana de predomínio venoso. Na observação inicial por Oftalmologia apresentava acuidade visual 10/10 bilateralmente, sem correção; fundo de olho esquerdo com hemorragia na hemiretina inferior, com tortuosidade vascular e vitrite associada. Ao exame objetivo salientava-se a presença de discretas pápulas na face, telangiectasias da face, membros superiores e dorso; adenopatias axilares bilaterais de consistência duro-elástica uma das quais dolorosa, sem outras alterações. Do estudo efectuado salientava-se trombocitopenia (121000/ uL) com anticorpos anti-plaquetários positivos, função renal, hepática e transaminases normais. VSG $42 \mathrm{~mm}$, lgE aumentada (> $5000 \mathrm{IU} / \mathrm{L}$, com valor confirmado e sem eosinofilia associada) e electroforese das proteínas com diminuição da 
albumina e aumento discreto policlonal de lgG (1830 mg/ dL) com subclasse G3 diminuída (34, 6 mg/dL, 41-129). Avaliação de C3 e C4 normal com atividade do complemento total-via clássica $>210$ unidades CAE (normal 63-145 unid. CAE). 0 estudo de imunofenotipagem dos linfócitos evidenciou aumento significativo de CD23 nos linfócitos B; proporção de células Th17 dentro da normalidade. Fator reumatóide, anticorpos anti cardiolipina lgG e IgM, anti Beta 2 glicoproteína I lgG e IgM, anti-nucleares, anti-citoplasma de neutrófilo (anti-MPO e anti-PR3), anti-dsDNA, anti-SSA, anti-SSB, anti-RNP, TASO, pesquisa de imunocomplexos circulantes e HLA B51 negativos. Adenosina deaminase plasmática e Enzima Conversora da Angiotensina dentro dos valores normais. As serologias revelaram-se lgM negativas e IgG positivas para Toxocara canis, Toxoplasma, Epstein-Barr e Citomegalovírus; VIH, VDRL e anticorpos IgG e IgM para Borrelia burgdoferi negativos. Anticorpos IgE dirigidos a Aspergillus fumigatus $0,08 \mathrm{UK} / \mathrm{L}$ (classe $0<0,35$ ), com título de lgG <1/80 por diluição. 0 exame parasitológico de fezes foi negativo. Efetuou Raio $X$ tórax (sem evidência de lesões pleuroparenquimatosas ou complexo de Gohn visível) e prova de Mantoux, que foi positiva (20 mm), tendo posteriormente efectuado o teste IGRA (Interferon Gamma Release Assay), igualmente positivo. Neste contexto, a doente foi enviada ao Centro de Diagnóstico Pneumológico, tendo cumprido terapêutica com isoniazida $300 \mathrm{mg} /$ dia durante 6 meses. Realizou ecografia abdominal que não mostrou organomegalias e TAC tórax onde se descreveram incipientes bronquiectasias cilíndricas bilaterais, algumas formações ganglionares ao longo da cadeia paratraqueal direita e ao nível das axilas que atingiam dimensões no limite superior da normalidade e presença de resquício tímico. 0 estudo genético permitiu excluir mutações no gene STAT 3 (signal transducer and activator of transcription 3 gene) e DOCK8 (dedicator of cytokinesis 8 gene). Realizou angiografia ocular que revelou no olho direito embainhamento venoso (com predomínio na veia temporal inferior) e no olho esquerdo, embainhamento e tortuosidade inicial na veia temporal superior, com difusão tardia em todos os campos (Figura 1).

Foi iniciada laserterapia, com boa evolução das lesões oculares, acuidade visual 10/10 OD e 9/10 OE. A doente manteve IgE persistentemente elevada (>5000 KU/L), evoluindo com infeções respiratória e urinárias de repetição.

\section{Discussão}

A investigação etiológica da vasculite retiniana é extensa obrigando a exploração de possíveis causas infeciosas (nomeadamente infeções bacterianas, víricas, parasitárias e riquetsioses), inflamatórias (Sarcoidose, Lupus Eritematoso Sistémico, Granulomatose de Wegener, Poliarterite nodosa, Síndrome de Sjogren, Artrite Reumatóide, entre outras), neoplásicas (linfoma ocular, síndroma paraneoplásico), neurológicas (esclerose múltipla) e oculares isoladas. ${ }^{1} 0$ atingimento predominante do compartimento venoso tem sido descrito em associação a doença de Behçet, tuberculose, sarcoidose, esclerose múltipla, doença de Eales (vasculite imuno mediada em doentes com hipersensibilidade à tuberculina) e infeção por VIH. No caso apresentado foi efetuado um estudo abrangente que permitiu descartar uma vasta panóplia de causas infeciosas e inflamatórias, destacando-se o diagnóstico de tuberculose latente, deteção de hipergamaglobulinémia $\mathrm{E}$ e de trombocitopenia imune.

Embora o Raio X não tenha demonstrando qualquer evidência que traduza tuberculose pulmonar em atividade ou infeção no passado, uma vez que a prova de Mantoux foi positiva (confirmado com IGRA), foi iniciada terapêutica antibacilar. Podem ocorrer manifestações oculares de tuberculose

Figura 1. Angiografia ocular

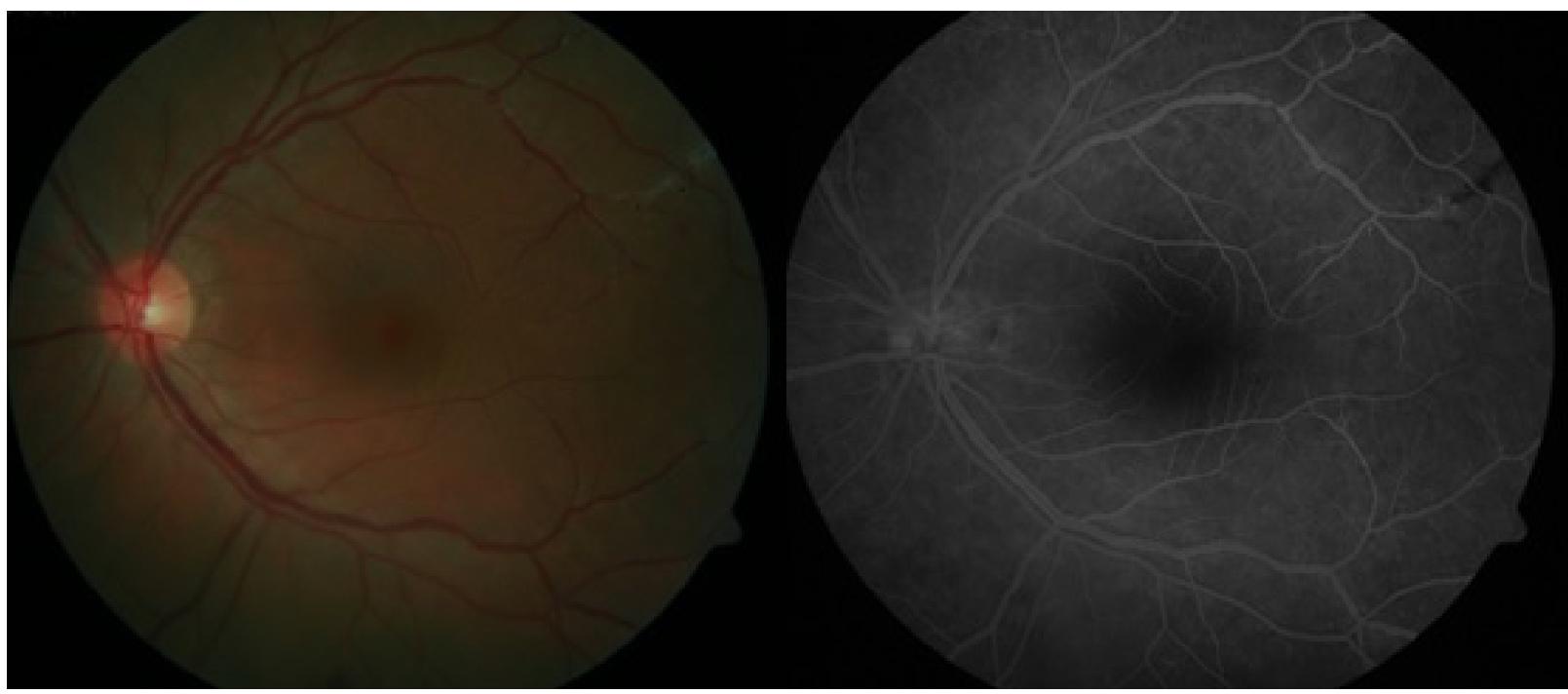


em contexto de infeção directa ou mecanismos de hipersensibilidade aos antigénios das micobactérias quando não há lesão ativa sistémica ou é considerada inativa, embora, no caso em análise, 0 aspeto das lesões não seja sugestivo de tuberculose ocular. 0 diagnóstico definitivo requereria a identificação do M. tuberculosis no tecido ou fluido ocular; não obstante, dada a morbilidade associada à sua colheita, 0 diagnóstico é maioritariamente presuntivo, não sendo provado pela ausência/presença de tuberculose extra-ocular. 0 seu tratamento consiste em corticoterapia sistémica e anti-bacilares. ${ }^{1}$ Também associada à infeção por M. tuberculosis, está descrita elevação dos valores de $\operatorname{lgM}, \lg A$ e IgE (200-444 IU/L), ${ }^{2,3}$ com redução desses mesmos valores após tratamento. ${ }^{3}$ Comparativamente ao descrito na literatura associado à tuberculose, a doente apresentava lgE elevada numa magnitude muito superior (>5000 IU/L), que não se modificou após tratamento com isoniazida, o que, aliado ao aspecto das lesões oculares, obrigou à consideração de outros diagnósticos, após exclusão de doença parasitária. ${ }^{4}$

Pelos sinais, sintomas associados e ausência de eosinofilia associada, tornou-se pouco provável diagnóstico de doença de Kimura, síndroma de Churg-Strauss e dermatite atópica (e outras formas de atopia). Dentro das causas de imunodeficiência primária associadas a elevação de lg E inclui-se o Síndroma de Wiskott-Aldrich, associado ao cromossoma X; Síndroma de Netherton, doença autossómica recessiva caracterizada por "cabelos em bambu", ictiose, atopia, eosinofilia e infeções recorrentes; Síndroma de Ommen, distinguido por eritrodermia exsudativa com descamação generalizada, hepatoesplenomegalia, infeções bacterianas de repetição e diarreia refratária; Síndrome de Nezel (forma menos severa que o Síndroma de Ommen) e Síndroma de Hiper-IgE. ${ }^{4} 0$ Síndroma de Hiper-lgE apresenta-se de forma autossómica dominante (mutações em STAT 3) ou recessiva (mutações em DOCK 8 ou TYK2- tyrosine kinase 2 gene). ${ }^{4-8} \mathrm{~A}$ forma dominante é caracterizada por alterações do esqueleto (escoliose, fraturas com trauma minor, osteopenia, hiperextensibilidade e doença articular degenerativa), do tecido conjuntivo, infeções pulmonares recorrentes (principalmente por $S$. aureus) e eczema (habitualmente marcado e presente logo no início de vida). A forma autossómica recessiva apresenta-se com infeções cutâneas estafilocócicas, infeções víricas recorrentes, anomalias do sistema nervoso central e vasculites. Alterações comuns consistem em anomalias faciais grosseiras e retenção da dentição de leite. Existe um maior risco associado de desenvolvimento de neoplasias, nomeadamente Linfoma não Hodgkin, de Hodgkin, leucemia, carcinoma da vulva, fígado e do pulmão. ${ }^{7}$ 0 diagnóstico é baseado em achados clínicos, laboratoriais, tendo sido proposto um score composto por critérios clínicos e laboratoriais, estando descrita de elevada probabilidade e identificação do fenótipo com pontuação igual ou superior a 15; e testes genéticos, tendo em consideração que não se encontra a mutação responsável em $50 \%$ dos casos. ${ }^{9}$ Não existe tratamento dirigido, sendo a abordagem dirigida à prevenção e tratamento de infeções. ${ }^{4-9}$

Apesar do quadro da doente não se enquadrar nas manifestações graves associadas à última síndroma, compreende, de forma geral, sinais e sintomas mais ligeiros associados a uma elevação marcada dos níveis de lgE, pontuando 16 pontos no score clinicolaboratorial pelo nível de lgE e presença de bronquiectasias, não tendo sido atribuída pontuação pela presença de escoliose e infeções por falta de registo/informação médica. Dada a pouca rentabilidade do estudo genético, optou-se por não progredir para o estudo de mutações menos frequentes, optando-se pelo seguimento da doente, nomeadamente no que diz respeito ao tratamento e prevenção de complicações infeciosas e despiste de neoplasias.

\section{Conclusão}

A vasculite ocular pode representar a primeira manifestação de um vasto número de patologias, pelo que é necessário uma abordagem/marcha diagnóstica abrangente. Tendo em conta a avaliação clínica, resultado do estudo efetuado, score clinicolaboratorial e evolução da doente, conclui-se pelo diagnóstico de fenótipo altamente provável de Hiper-lgE, que é muitas vezes descrita como um grupo de patologias semeIhantes, cuja heterogeneidade decorre de alterações genéticas diferentes, sendo o seu tratamento dirigido à prevenção e tratamento de infeções.

\section{Bibliografia}

1. Abu El-Asrar AM, Herbort CP, Tabbara KF. Retinal vasculitis. Ocul Immunol Inflamm. 2005; 13(6): 415-33

2. Rohini K, Srikumar PS, Mahesh KA. A Study on the Serum Immunoglobulin Levels in Pulmonary Tuberculosis Patients. Int J Biosci Biochem Bioinforma. 2012; 2(4): 280281.

3. Ohrui T, Zayasu K, Sato E, Matsui T, Sekizawa K, Sasaki H. Pulmonary tuberculosis and serum IgE. Clin Exp Immunol. 2000; 122: 13-15

4. Yasharpour M, Agarwal S, Jerome D, Yel L. Is It Hyper IgE Syndrome Or Something Else? MOJ Immunol. 2014; 1(2): 2003-2006.

5. Szczawinska-Poplonyk A, Kycler Z, Pietrucha B, Heropolitanska-Pliszka E, Breborowicz $A$, Gerreth $K$. The hyperimmunoglobulin $E$ syndrome-clinical manifestation diversity in primary immune deficiency. Orphanet J Rare Dis. 2011; 6(1): 76.

6. Cruz-Portelles A, Estopiñan-Zuñiga D. A new case of Job's syndrome at the clinic: A diagnostic challenge. Rev Port Pneumol. 2014; 20(2): 107-110.

7. Paulson ML, Freeman AF, Holland SM. Hyper lgE syndrome: an update on clinical aspects and the role of signal transducer and activator of transcription 3. Curr Opin Allergy Clin Immunol. 2008; 8(6): 527-33.

8. Grimbacher B, Holland SM, Puck JM. Hyper-lgE syndromes. Immunol Rev. 2005 203: 244-250.

9. Gamberale A, Moreira I, Bartoletti B, Cruz V, Bezrodnik L, Alberti F et al. Síndrome de Job asociado a tuberculose miliar. Medicina (B. Aires). 2014; 74 (4): 311-314 